\title{
One-port (uniportal) video-assisted thoracic surgical resections-A clear advance
}

\author{
Gaetano Rocco, MD, FRCSEd, FETCS
}

\begin{abstract}
One-port (uniportal) video-assisted thoracic surgery (VATS) consists of approaching an intrathoracic target lesion through a sagittal, craniocaudal plane through 1 single-port incision. The use of articulating instruments inserted parallel to the videothoracoscope enables the surgeon to mimic inside the chest the maneuvers that are usually performed during open surgery. Through this VATS approach, several thoracic conditions can be addressed, including lung cancer in selected patients. Unlike conventional, 3-port VATS, the uniportal VATS technique enables the surgeon to bring the operative fulcrum inside the chest when the target lunge lesion is approached through a sagittal plan, thanks to articulating instruments. Uniportal wedge VATS resections of peripheral nodules can help in solving diagnostic dilemmas, be of therapeutic benefit, and provide tissue for biomolecular studies. (J Thorac Cardiovasc Surg 2012;144:S27-31)
\end{abstract}

A MEDLINE search of the term "single port surgery" performed in August 2011 revealed more than 1200 results. In particular, several general surgical, urologic, and gynecologic papers are focused on the technique and instrumentation of single-port laparoscopic surgery. ${ }^{1}$ Single-access concept merges with natural-orifice transluminal endoscopic surgery by virtue of the transumbilical abdominal procedures recently performed and described in detail. ${ }^{2}$ Furthermore, single-port robotic devices are being tested for use in abdominal robot-assisted surgery. ${ }^{3}$ In this setting, the latest technologic refinements aim at facilitating concomitant introduction and operative use of more than one instrument at a time in addition to the selected visualization system. Specific devices have been studied for tie-knotting, stapling, and tissue handling with superb results in terms of maneuverability and user-friendliness. When it comes to single-port (or uniportal) thoracoscopic surgery, the technologic gap is obvious. The surgical technique and current indications for single-port (uniportal) operative videoassisted thoracic surgery (VATS) have been described in detail elsewhere. ${ }^{4,5}$ Nevertheless, thoracic surgeons still use adapted instruments from general surgery despite the potential use of single-port operative VATS for many purposes. ${ }^{6}$ Indeed, diagnostic uses of uniportal VATS include diagnosis and treatment of pleural, mediastinal, and chest wall conditions. ${ }^{7-12}$ Uniportal pulmonary resections vary from wedge resections for diagnostic purposes to wedge for pneumothorax and solitary pulmonary nodules located in the outer third of the lung. ${ }^{4,5}$

\footnotetext{
From the Division of Thoracic Surgery, Department of Thoracic Surgery and Oncology, National Cancer Institute, Pascale Foundation, Naples, Italy. Disclosures: Author has nothing to disclose with regard to commercial support. Presented at the 3rd International Minimally Invasive Thoracic Surgery Summit, Boston, Massachusetts, October 7-8, 2011.

Received for publication Sept 27, 2011; revisions received March 23, 2012; accepted for publication June 5, 2012; available ahead of print June 29, 2012.

Address for reprints: Gaetano Rocco, MD, FRCSEd, FETCS, Division of Thoracic

Surgery, National Cancer Institute, Pascale Foundation, Via Semmola 81, 80131

Naples, Italy (E-mail: Gaetano.Rocco@btopenworld.com).

$0022-5223 / \$ 36.00$

Copyright (c) 2012 by The American Association for Thoracic Surgery

http://dx.doi.org/10.1016/j.jtcvs.2012.06.006
}

\section{SURGICAL INSTRUMENTATION AND TECHNIQUE}

Technical mainstays of operative uniportal VATS include a single incision anywhere from 0.5 to $1 \mathrm{~cm}$ (ie, sympathectomy) up to $2.5 \mathrm{~cm}$ wide, blunt dissection to the pleural plane, and simultaneous introduction of articulating operative instruments parallel to a $5-\mathrm{mm}$ (or lesser size) $0^{\circ}$ or $30^{\circ}$ videothoracoscope. ${ }^{4,5}$ The placement of the incision depends on the location of the target area in the chest. In this setting, careful interpretation of chest computed tomography is mandatory, bearing in mind that an adequate distance between the single port and the target area needs to be allowed to avoid instrument-videothoracoscope interference. ${ }^{4,5}$ As a rule, the most appropriate intercostal space identified at a latitudinal, horizontal level is between the fourth and the sixth. The vertical, longitudinal line is selected either anterior or posterior to the midscapular line. ${ }^{1,4,5}$ Usually, posteriorly located lesions are approached through incisions located anterior to the midscapular line-generally along the midaxillary line (Table 1).

Uniportal VATS wedge pulmonary resection technique is based on a completely different geometric concept compared with conventional 3-port VATS (Figure 1). In fact, the approach to the target lesion in the lung is substantially similar to the approach that the surgeon would use in open surgery. In the latter scenario, the visualization of the target lesion and its surgical removal would occur along the same axis. Therefore, the target lesion in the lung would be elevated with forceps perpendicularly from the parenchymal profile and resected by applying a stapler (or a curved clamp and oversewn) at the base of this newly created, cone-shaped parenchymal area. A pure geometric explanation of the potential advantage of uniportal VATS compared with conventional 3-port VATS lies in the projective plane of the sagittal approach to the target lesion, which preserves the depth of intraoperative visualization provided by the currently available 2-dimensional video monitors. ${ }^{4,5,13}$ Conversely, the torsion plane created along the lozenge 


\section{Abbreviation and Acronym \\ VATS $=$ video-assisted thoracic surgery}

obtained with conventional VATS using the laterolateral approach hampers a distinct visualization of the perspective, deep operative field. ${ }^{4,5,13}$ The single incision needs to be placed on a direct line leading to the target area but at a distance sufficient to allow for deploying articulating arms of endograsps and endostaplers. ${ }^{4,5}$ In fact, in the lateral decubitus position, these articulating instruments, like robotic arms, clearly adapt to the fixed dome-shaped volumetry of the pleural cavity. ${ }^{5}$ More recently, following the geometric principles of uniportal VATS wedge resection, single-access lobectomies have been described as a part of the surgical armamentarium of a VATS lobectomy program in Spain. ${ }^{14}$

\section{INTRAOPERATIVE AND PERIOPERATIVE MANAGEMENT FOR UNIPORTAL VATS}

Traditional VATS can be performed safely under local anesthesia and sedation. ${ }^{15}$ Uniportal VATS can be done under locoregional anesthesia and without intubation in the awake patient for most of the already reported indications, including wedge pulmonary resection. ${ }^{16}$ Furthermore, a no-drain policy can be adopted for straightforward wedge resections along the same line as for uniportal sympathectomy or uniportal biopsy or removal of mediastinal lymph nodes. ${ }^{16,17}$ Locoregional anesthesia is usually administered through an epidural catheter introduced at the level of the fourth to fifth thoracic vertebrae. The catheter is left in place even though only a single-shot injection of local anesthetic is injected, which is supposed to ensure pain control for at least 3 hours. In addition, the epidural catheter may contribute to pain management in the event of an unanticipated conversion to thoracotomy. ${ }^{16,18}$

\section{PAIN, PARESTHESIA, AND COSTS AFTER UNIPORTAL VATS}

Although no prospective, randomized trials have been generated so far to compare uniportal versus conventional VATS, the evidence in the literature is growing as to the lesser impact of uniportal VATS in terms of postoperative pain and paresthesia. ${ }^{8,19,20}$ Conventional VATS seems to induce less postoperative pain than do thoracotomy or hybrid procedures. ${ }^{21}$ Reportedly, residual pain after VATS may subside in 12 weeks after surgery. ${ }^{21}$ Injury of the intercostal neurovascular bundle is the major determinant of postoperative complaints, ${ }^{21}$ no matter how big the port incision compared with conventional port size. ${ }^{22}$ Indeed, $50 \%$ of the patients subjected to needlescopic VATS for palmar
TABLE 1. Criteria for single-port location

\begin{tabular}{|c|c|c|c|}
\hline Procedure & $\begin{array}{c}\text { Intercostal } \\
\text { space }\end{array}$ & Line & Decubitus \\
\hline Bullectomy & Fifth & $\begin{array}{l}\text { Postero-median } \\
\text { axillary line }\end{array}$ & Lateral \\
\hline \multicolumn{4}{|l|}{$\begin{array}{l}\text { Lung biopsy-lung } \\
\text { resection }\end{array}$} \\
\hline Upper lobes & Fifth & Median axillary line & Lateral \\
\hline $\begin{array}{l}\text { Middle } \\
\text { lobe - Lingula }\end{array}$ & Fifth-sixth & $\begin{array}{l}\text { Posterior } \\
\text { axillary-scapular line }\end{array}$ & Lateral \\
\hline Lower lobes & Fourth & $\begin{array}{l}\text { Median-posterior } \\
\text { axillary lane }\end{array}$ & Lateral \\
\hline \multicolumn{4}{|l|}{$\begin{array}{l}\text { Mediastinal } \\
\text { node biopsy }\end{array}$} \\
\hline $\begin{array}{l}\text { Middle } \\
\text { mediastinum }\end{array}$ & Fifth & Scapular line & Lateral \\
\hline $\begin{array}{l}\text { Posterior } \\
\text { mediastinum }\end{array}$ & Fifth & Posterior axillary line & Supine \\
\hline Sympathectomy & Third & Axillary hair line & Lateral \\
\hline Pericardial window & Fifth & Axillary line & $\begin{array}{l}\text { Supine, } \\
\text { semilateral }\end{array}$ \\
\hline
\end{tabular}

hyperhydrosis had significant paresthesia, especially for the incisions placed in the mammary fold. ${ }^{22}$ After 1 year, $17 \%$ of the patients in the series reported by Sihoe and colleagues $^{22}$ still had residual paresthesia. The authors concluded that there was no difference between needlescopic and conventional 3-port VATS in terms of postoperative paresthesia. ${ }^{22}$ Passlick and associates ${ }^{23}$ reported on chronic postoperative pain after 3-port VATS in the management of pneumothorax. In the reported series, 12-mm, 10-mm, and 5 -mm trocars had been used in their patients; $32 \%$ of them reported residual chronic pain particularly at the port sites. ${ }^{23}$ The authors concluded that these findings had to be taken into consideration when offering pneumothorax patients the option of chest drain or minimally invasive procedure. ${ }^{23}$ In this setting, the awake uniportal technique may settle the issue of whether to surgically manage first episodes of pneumothorax. ${ }^{18}$ Uniportal VATS could be performed through the same incision of the chest drain placed in the accident and emergency department or, in young female patients, a cosmetically acceptable port site can be selected avoiding the mammary area and the attendant paresthesia. ${ }^{22}$

In an era of managed care, uniportal VATS needed to be compared with conventional VATS as to duration of hospitalization and postoperative costs. ${ }^{24}$ In this setting, Salati and colleagues ${ }^{24}$ analyzed a small selected series of patients subjected to uniportal VATS for pneumothorax. Besides a significant difference in the incidence of postoperative paresthesia $(P<.0001)$, uniportal VATS patients had a shorter hospital stay $(P=.03)$ and generated lower 

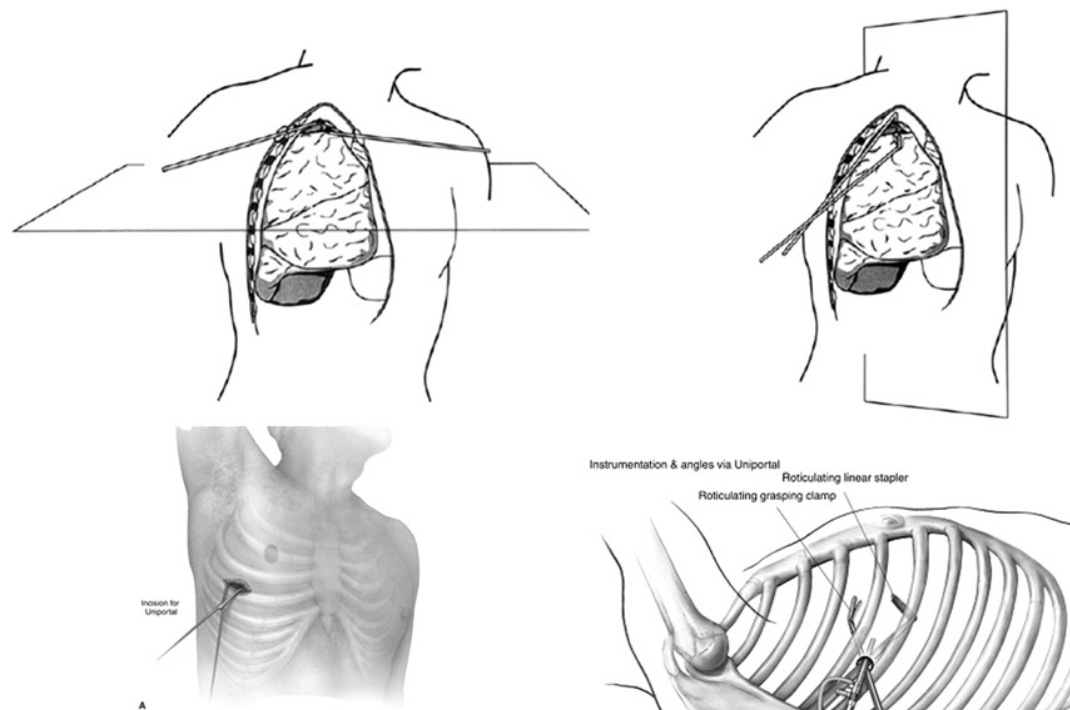

A
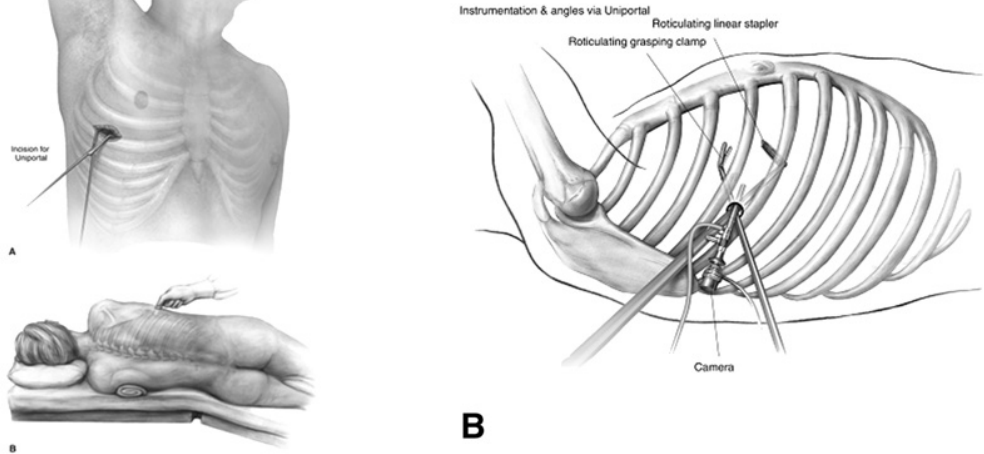

B

FIGURE 1. Technique of uniportal video-assisted (VATS) pulmonary wedge resection. Compared with a laterolateral approach in conventional, 3-port VATS, a caudo-cranial-sagittal approach to the target lesion in the lung is selected. (Uppermost diagrams A and B: reprinted with permission ${ }^{4}$ ). Through a single 2- to $2.5-\mathrm{cm}$ incision, the videothoracoscope and the operative instruments are introduced into the chest. The relative position of the instrumentsthoracoscope ensemble can be varied according to the selected parenchymal target area and the indication of uniportal VATS. (Lowermost diagrams: reprinted with permission ${ }^{5}$ ).

postoperative costs $(P=.03) .{ }^{24}$ In addition, in a series from the Mayo Clinic of 155 patients subjected to sympathotomy at the level of the first or second thoracic vertebrae, no intercostal neuralgia was noted perioperatively or at 34 months' median follow-up. ${ }^{20}$

\section{SPECIAL ISSUES}

As with conventional VATS, the ability to palpate the lung is limited-but not impossible-through uniportal VATS. ${ }^{4,5}$ Accordingly, the identification of peripheral pulmonary nodules must rely on visual inspection or on their preoperative or intraoperative marking. ${ }^{17}$ Recently, an articulating endoscopic ultrasound probe was used to detect peripheral nodules during uniportal VATS. ${ }^{17}$ Endoscopic ultrasounds have proved useful in outlining ground glass opacities in the pulmonary parenchyma. ${ }^{17}$ The addition, the articulating endoscopic ultrasound probe of an echo Doppler device allows for assessing the vascular supply (hence, a hint on the malignant nature of the lesion) and the depth of the nodule. ${ }^{17}$ In this context, operative uniportal VATS can be an interesting approach to primary and secondary lung cancers, with both a diagnostic and therapeutic intention in patients with borderline cardiorespiratory function or advanced age. ${ }^{16,17,24}$ However, the established concept of targeted therapy for patients with non-small cell lung cancer based on new clinical and biomolecular evidence has prompted the resurgence of interest for sublobar pulmonary resections for early-stage non-small cell lung cancer. ${ }^{25}$ In this context, operative uniportal VATS could be considered as a means to resect nodules located in the outer third of the lung and less than $2 \mathrm{~cm}$ in diameter provided that the following are true: (1) pure bronchoalveolar carcinoma histology, (2) ground glass opacity appearance for more than $50 \%$ of the lesion as per computed tomographic scan assessment, (3) extended doubling time ( $>400$ days), and (4) resection margin of at least $2 \mathrm{~cm}$ or equal to/greater than the size of the nodule. ${ }^{25}$

\section{THE PERSPECTIVE VALUE OF SINGLE-ACCESS VATS IN THORACIC SURGERY}

In conclusion, uniportal VATS represents a clear advantage for selected indications and a valuable addition to the surgical armamentarium complementing other single-port/ single-access procedures, such as endobronchial ultrasound biopsy of mediastinal masses, video-assisted mediastinoscopy, video-assisted mediastinoscopic lymphadenectomy, and transcervical extended mediastinal lymphadenectomy (Table 2). Technologic advancements aimed at manufacturing custom-made instrumentation for thoracoscopic surgery will be equally decisive in facilitating the single-port technique under local or locoregional anesthesia. However, 
TABLE 2. Intrathoracic conditions, suggested anesthetic management, chest drain policy, and operative settings for uniportal VATS

\begin{tabular}{|c|c|c|c|c|c|}
\hline Condition & Uniportal VATS & Anesthetic modality & Drain & Setting & Notes \\
\hline Pleural effusion & Diagnostic & $\begin{array}{l}\text { Local } \\
\text { Locoregional }\end{array}$ & Yes & Outpatient & - \\
\hline Trauma & Diagnostic & General & Yes & In Hospital & Hemodynamic stability \\
\hline Pericardial effusion & Operative (window) & $\begin{array}{l}\text { Locoregional } \\
\text { General }\end{array}$ & Yes & In Hospital & Hemodynamic stability \\
\hline Stage I/II empyema & Diagnostic/operative (loculations) & $\begin{array}{l}\text { Local } \\
\text { Locoregional }\end{array}$ & Yes & In Hospital & - \\
\hline Interstitial lung disease & Operative (wedge) & Locoregional & No & Outpatient & - \\
\hline Sympathectomy & Operative & Locoregional & No & Outpatient & Bilateral \\
\hline Nodal biopsy & Diagnostic & $\begin{array}{l}\text { General } \\
\text { Locoregional }\end{array}$ & No & In Hospital & - \\
\hline Lymphadenectomy & Operative & General & Yes & In Hospital & - \\
\hline Primary pneumothorax & Operative (pleurectomy/abrasion) & Locoregional & Yes & $\begin{array}{l}\text { In hospital } \\
\text { Outpatient }\end{array}$ & - \\
\hline Peripheral subpleural nodule & Operative & Locoregional & No & $\begin{array}{l}\text { In hospital } \\
\text { Outpatient }\end{array}$ & Intraoperative ultrasound \\
\hline Peripheral nodule (outer third of the lung) & Operative & $\begin{array}{l}\text { General } \\
\text { Locoregional }\end{array}$ & No & $\begin{array}{l}\text { In hospital } \\
\text { Outpatient }\end{array}$ & Intraoperative ultrasound \\
\hline Chest wall lesion & Operative & General & Yes & In hospital & - \\
\hline
\end{tabular}

VATS, Video-assisted thoracic surgery.

further developments in the use of uniportal VATS will be represented by its use as the minimally invasive technique of choice for pulmonary tissue procurement aimed at biomolecular investigations, as the geometric approach to the chest cavity useful to minimize surgical trauma during robotic procedures, and, possibly, as the procedure paving the way to natural-orifice transluminal endoscopic surgery-intuitively, a single-access procedure-in our domain.

\section{References}

1. Curcillo PG 2nd, Podolsky ER, King SA. The road to reduced port surgery: from single big incisions to single small incisions, and beyond. World J Surg. 2011;35: 1526-31.

2. Lee YS, Kim JH, Moon EJ, Kim JJ, Lee KH, Oh SJ, et al. Comparative study on surgical outcomes and operative costs of transumbilical single-port laparoscopic appendectomy versus conventional laparoscopic appendectomy in adult patients. Surg Laparosc Endosc Percutan Tech. 2009;19:493-6.

3. Wren SM, Curet MJ. Single-port robotic cholecystectomy: results from a first human use clinical study of the new da Vinci single-site surgical platform. Arch Surg. 2011;146:1122-7.

4. Rocco G, Martin-Ucar A, Passera E. Uniportal VATS wedge pulmonary resections. Ann Thorac Surg. 2004;77:726-8.

5. Rocco G. Single port video-assisted thoracic surgery (uniportal) in the routine general thoracic surgical practice. Op Tech Thorac Cardiovasc Surg. 2009;14: 326-35.

6. Berlanga LA, Gigirey O. Uniportal video-assisted thoracic surgery for primary spontaneous pneumothorax using a single-incision laparoscopic surgery port: a feasible and safe procedure. Surg Endosc. 2011;25:2044-7.

7. Rocco G, La Rocca A, La Manna C, Scognamiglio F, D'Aiuto M, Jutley R, et al. Uniportal video-assisted thoracoscopic surgery pericardial window. J Thorac Cardiovasc Surg. 2006;131:921-2.

8. Jutley RS, Khalil MW, Rocco G. Uniportal vs standard three-port VATS technique for spontaneous pneumothorax: comparison of post-operative pain and residual paraesthesia. Eur J Cardiothorac Surg. 2005;28:43-6.

9. Rocco G, Khalil M, Jutley R. Uniportal video-assisted thoracoscopic surgery wedge lung biopsy in the diagnosis of interstitial lung diseases. J Thorac Cardiovasc Surg. 2005;129:947-8.
10. Rocco G, Brunelli A, Jutley R, Salati M, Scognamiglio F, La Manna C, et al. Uniportal VATS for mediastinal nodal diagnosis and staging. Interact Cardiovasc Thorac Surg. 2006;5:430-2.

11. Givigliano F, La Rocca A, La Manna C, Busiello L, Longo F, Scognamiglio F, et al. Minimally invasive combined approach for an hourglass-shaped mass at the thoracic inlet. J Thorac Cardiovasc Surg. 2007;134:528-9.

12. Jutley RS, Cooper G, Rocco G. Extending video-assisted thoracoscopic surgery for trauma: the uniportal approach. J Thorac Cardiovasc Surg. 2006; 131:1424.

13. Bertolaccini L, Rizzardi G, Terzi A. Single-port video-assisted thoracic surgery resection: the Copernican revolution of a geometrical approach in thoracic surgery? Interact Cardiovasc Thorac Surg. 2011;12:516.

14. Gonzalez-Rivas D, Paradela M, Fieira E, Velasco C. Single-incision videoassisted thoracoscopic lobectomy: initial results. J Thorac Cardiovasc Surg. 2012;143:745-7.

15. Katlic MR, Facktor MA. Video-assisted thoracic surgery utilizing local anesthesia and sedation: 384 consecutive cases. Ann Thorac Surg. 2010; 90:240-5.

16. Rocco G, Romano V, Accardo R, Tempesta A, La Manna C, La Rocca A, et al. Awake single-access (uniportal) video-assisted thoracoscopic surgery for peripheral pulmonary nodules in a complete ambulatory setting. Ann Thorac Surg. 2010;89:1625-7.

17. Rocco G, Cicalese M, La Manna C, La Rocca A, Martucci N, Salvi R. Ultasonographic identification of peripheral pulmonary nodules through uniportal videoassisted thoracic surgery. Ann Thorac Surg. 2011;92:1099-101.

18. Rocco G, La Rocca A, Martucci N, Accardo R. Awake single-access (uniportal) video-assisted thoracoscopic surgery for spontaneous pneumothorax. J Thorac Cardiovasc Surg. 2011;142:944-5.

19. Salati M, Brunelli A, Rocco G. Uniportal video-assisted thoracic surgery for diagnosis and treatment of intrathoracic conditions. Thorac Surg Clin. 2008;18: 305-10.

20. Atkinson JL, Fode-Thomas NC, Fealey RD, Eisenach JH, Goerss SJ. Endoscopic transthoracic limited sympathotomy for palmar-plantar hyperhidrosis: outcomes and complications during a 10-year period. Mayo Clin Proc. 2011; 86:721-9.

21. Miyazaki T, Sakai T, Tsuchiya T, Yamasaki N, Tagawa T, Mine M, et al. Assessment and follow-up of intercostal nerve damage after video-assisted thoracic surgery. Eur J Cardiothorac Surg. 2011;39:1033-9.

22. Sihoe AD, Cheung CS, Lai HK, Lee TW, Thung KH, Yim AP. Incidence of chest wall paresthesia after needlescopic video-assisted thoracic surgery for palmar hyperhidrosis. Eur J Cardiothorac Surg. 2005;27:313-9. 
23. Passlick B, Born C, Sienel W, Thetter O. Incidence of chronic pain after minimalinvasive surgery for spontaneous pneumothorax. Eur J Cardiothorac Surg. 2001; 19:355-8.

24. Salati M, Brunelli A, Xiumè F, Refai M, Sciarra V, Soccetti A, et al. Uniportal video-assisted thoracic surgery for primary spontaneous pneumothorax: clinical and economic analysis in comparison to the traditional approach. Interact Cardiovasc Thorac Surg. 2008;7:63-6.

25. Ettinger DS, Akerley W, Bepler G, Blum MG, Chang A, Cheney RT, et al; NCCN Non-Small Cell Lung Cancer Panel Members. Non-small cell lung cancer. J Natl Compr Canc Netw. 2010;8:740-801. 